\title{
Enhancing Transient Stability in Limited Variable Speed Induction Generator (Optislip) Based Wind Turbine
}

\section{(Case study: Binalood Wind Farm)}

\author{
Omid Rahat \\ Department of Electrical Engineering \\ Ramhormoz Branch, Islamic Azad University \\ Ramhormoz, Iran \\ Rahat_omid@yahoo.com
}

\author{
Iman Riazy \\ Department of Electrical Engineering \\ Ramhormoz Branch, Islamic Azad University \\ Ramhormoz, Iran \\ imanriazy@gmail.com
}

\begin{abstract}
Enormous penetration of wind power in power systems and its contribution in covering a major part of grid load demand, require higher stability during disturbances. The most important issue of wind generators is the early outage of several generating units when a sudden voltage drop occurs in the grid. Voltage drops near wind generators are mainly due to abrupt load rises and integration of large-scale factories and industrial units into the grid. In this paper, the case study of Binalood wind farm is studied, analyzed, and simulated. Then, various proposed methods are investigated in terms of stability enhancement such that when a disturbance appears near the Binalood wind farm, it can hold up its stability and connection to the grid. Simulations are carried out using Matlab and Simulink.
\end{abstract}

Keywords-Wind Farm; transient stability enhancement; Induction Generators; Optislip; Matlab; Simulink

\section{INTRODUCTION}

Binalood Wind Farm with a total capacity of 28.4 MW is comprised of 43 limited variable speed generating units (660 $\mathrm{kW}$ ) with a voltage level of $600 \mathrm{~V}$. This wind farm is located 55 $\mathrm{km}$ away from Mashhad City-Nishaboor Town Road in the Dizbad district which is one of the most appropriate regions for harvesting wind power in Iran. Various industrial parks and production firms are located near this wind farm, causing huge voltage drops when they are connected to the power grid. The major problem with this wind farm, since its establishment, is the early outage of some generating units when an abrupt voltage drop appears near it. In wind farms with induction generators, voltage reduction of generator terminals leads to reduced generated power and electromagnetic torque of the generator. The difference between electromagnetic and mechanical torques results in acceleration of the generator and slip rise which in turn increases reactive power extremely. Reactive power rise in a weak grid decreases voltage more sharply. Once a generator speed is out of control, reactive power consumption will increase and voltage reduction will be much more extreme. Sharp voltage drop may increase generator speed dramatically and then result in operation of protection systems and wind farm outage.

Due to the importance of stability enhancement issue in wind farms, numerous works have been conducted. For instance, in [1-4], angle change of turbine blades is suggested in order to reduce the input mechanical power into the generator when a fault occurs. In addition, the effect of improving control ring performance on tuning the angle of blades is highly considered. Conversely, authors in [3] had a completely different idea and assert that because this system is of mechanical type, delay in operation is unavoidable and it has no influence on stability improvement of the generating unit. Rather, it is advantageous in preventing generator acceleration after isolating that unit from the grid. In [1], beside angle change of blades, the use of SVC and rotor resistance rise are also suggested. This article considers a high capacity for SVC to maintain transient stability. Additionally, rotor resistance rise method specifies that this method is viable by inserting an external resistor in rotor circuit when a fault occurs. Normally, this resistor is in short-circuiting condition by a switch. In [2, 3], the performance of capacitor banks and SVC are compared. Also, it is mentioned that SVC not only increases stability, but also decreases dynamic voltage oscillations and, in turn, the quality of power delivered is improved.

In this paper, Binalood wind farm is simulated using realistic data. Then, a disturbance with a close-to real world characteristic is employed on the location of the wind farm and its stability is analyzed. Next, different methods are individually evaluated towards stability improvement and comparisons are made.

\section{BINALOOD WIND FARM}

Binalood wind farm with a capacity of $28.4 \mathrm{MW}$ is comprised of 43 generating units $(660 \mathrm{~kW})$. The power produced by the wind farm is delivered to the power grid 
through 132/20 kV Binalooed substation and two transmission lines (Shariati-Binalood and Attar-Binalood). Each generating units includes a turbine, gearbox, generator, step-up transformer, capacitor bank, RCC system, etc. Figure 1 depicts one-line diagram of the mentioned wind farm.

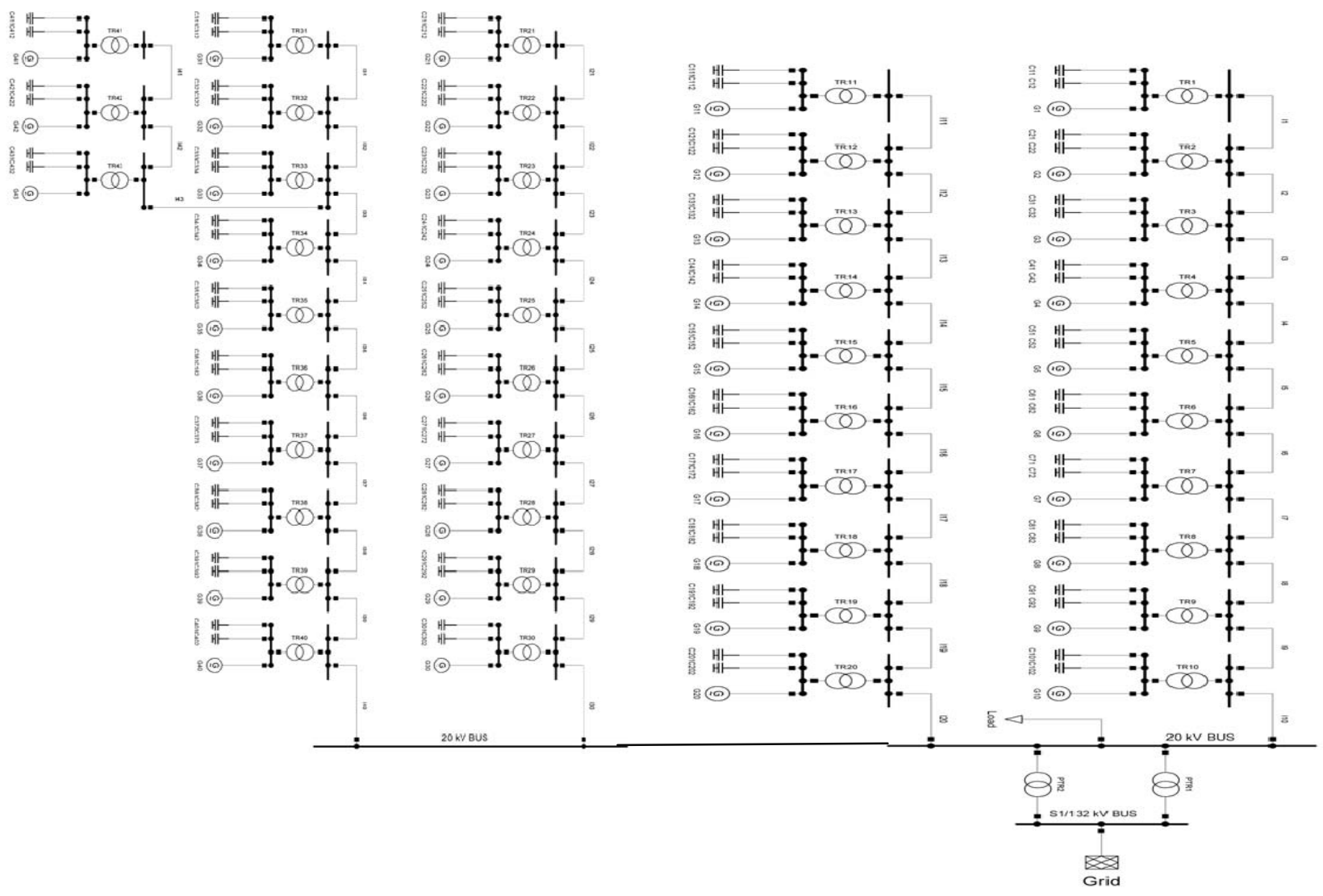

Fig. 1. One-line diagram of Binalood wind farm

\section{A. Turbine Model}

Wind turbine produces eclectic energy by transforming wind power into mechanical torque through the operation of blades. The amount of transformed energy by the rotor depends upon air density, rotor area, wind speed, aerodynamic coefficient of turbine blades and is obtained by [5]:

$$
p_{m}=\frac{1}{2} p A c_{P}(\lambda, \beta) V^{3}
$$

$C_{p}(\lambda, \beta)$ is different for various turbines and provided by the manufacturer in curves and/or mathematical relationships. The following exponential relationship is more general [6]"

$C_{P}=0.22\left(\frac{116}{\lambda_{l}}-0.4 \beta-5\right) e^{\frac{-12.5}{\lambda_{i}}} \quad, \quad \lambda_{l}=1 /\left(\frac{1}{\lambda+0.08 \beta}-\frac{0.035}{\beta^{3}+1}\right)$

The angle value is also determined by $\tau \eta \varepsilon$ control system of blades' angle. In order to obtain the output torque of the turbine, the following relationship is employed:

$$
T_{m_{(p u)}}=\frac{p_{m}(p u)}{\omega_{r}(p u)}
$$

The value of parameters and characteristics of the turbine are provided in Table I.

TABLE I. BINALOOD WIND FARM TURBINE CHARACTERISTICS

\begin{tabular}{|c|c|c|}
\hline$R=23.5 \mathrm{~m}$ & Cut in speed: $4 \mathrm{~m} / \mathrm{s}$ & $\omega \mathrm{r}=28.5 \mathrm{rpm}$ \\
\hline$\rho=1.225 \mathrm{~kg} / \mathrm{m} 3$ & Cut out speed: $25 \mathrm{~m} / \mathrm{s}$ & \\
\hline
\end{tabular}

\section{B. Drive-Train Model}

Two-mass model is utilized in modeling rotor, shaft, and gearbox which are named so-called Drive-Train. The use of this accurate model, instead of one-mass model, allows us to consider mechanical mode oscillations in stability studies because of shaft non-rigidity condition. In this model, the set of turbine and gearbox are considered as one mass; while, generator rotor and its equipment are taken as a separate mass (Figure 2). High speed shaft is also simulated as a non- rigidity object connecting the two mentioned masses. Regarding Figure 2 , following relationships may be written [7]: 


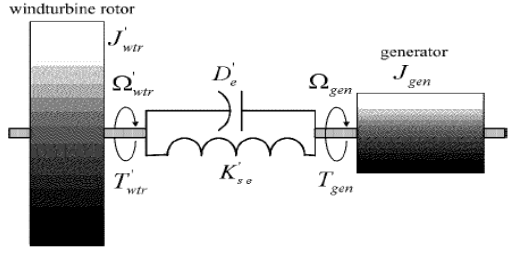

Fig. 2. Mechanical model of wind turbine shaft

$$
\begin{aligned}
& T_{t}^{\prime}=J_{t}^{\prime} \frac{d \omega_{t}^{\prime}}{d t}+D_{m}^{\prime}\left(\omega_{t}^{\prime}-\omega_{g}\right)+D_{t}^{\prime} \omega_{t}^{\prime}+k^{\prime}\left(\theta_{t}^{\prime}-\theta_{g}\right) \\
& -T_{g}=J_{g} \frac{d \omega_{g}}{d t}+D_{e}^{\prime}\left(\omega_{g}-\omega_{t}^{\prime}\right)+D_{g}^{\prime} \omega_{g}+k^{\prime}\left(\theta_{g}-\theta_{t}^{\prime}\right) \\
& \omega_{t}^{\prime}=\frac{d \theta_{t}^{\prime}}{d t}, \omega_{g}=\frac{d \theta_{g}}{d t}, k^{\prime}=\frac{k_{g} \times k_{t} / n^{2}}{k_{g}+k_{t} / n^{2}}, J_{t}^{\prime}=\frac{1}{n^{2}} J_{t} \\
& D_{t}^{\prime}=\frac{1}{n^{2}} D_{t}, D_{m}^{\prime}=\frac{1}{n^{2}} D_{m}
\end{aligned}
$$

where $\mathrm{n}$ denotes gearbox turn ratio, $T_{t}^{\prime}$ denotes wind turbine torque transferred to the generator shaft-side, $T_{g}$ denotes generator torque, $\omega_{t}^{\prime}$ denotes turbine rotor speed transferred to the generator shaft-side $J_{t}^{\prime}$ denotes turbine inertia moment transferred to the generator shaft-side, $J_{g}$ denotes generator rotor's inertia moment, $D_{m}^{\prime}$ denotes damping ratio of the shaft transferred to the generator shaft-side, $D_{t}^{\prime}$ denotes damping ratio of the turbine transferred to the generator shaft-side, $D_{g}$ denotes damping ratio of the generator shaft, $k_{t}$ denotes spring ratio transferred to the generator shaftside, $k_{g}$ denotes spring ratio of generator shaft, $k^{\prime}$ denotes total spring ratio (torsion spring ratio) that is obtained by equaling the spring ratio of generator shaft and turbine shaft. In these relationships, the quantities of low-speed shaft side (turbine shaft) are transferred to high-speed shaft side (generator shaft) (noted by " ' "). Table II provides parameters used in simulation.

TABLE II. DRIVE TRAIN CHARACTERISTICS

\begin{tabular}{|c|c|c|}
\hline$J_{t=277000 \mathrm{kgm} 2}^{\prime}$ & $\mathrm{Dm}=10 \mathrm{kNms} / \mathrm{rad}$ & $\mathrm{n}=52.65$ \\
\hline $\mathrm{k}=4330000 \mathrm{Nm} / \mathrm{rad}$ & $\mathrm{Dt}=1000 \mathrm{Nms} / \mathrm{rad}$ & $\mathrm{Jg}=29$ \\
\hline
\end{tabular}

\section{Generator Model}

In this research, the induction generator model available in Matlab/Simulink is used. The generator is modeled in 3-phase mode using the diagram shown in Figure 3 considering rotor and stator transient behaviors [8-10]. The generator used in Binalood wind farm is of winding type without brushes. The rotor resistor of this generator can be controlled by RCC system. The parameters used in the simulation are expressed in Table III.

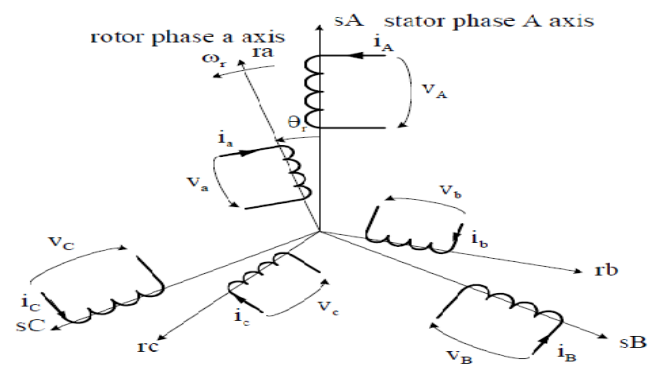

Fig. 3. Simplified diagram of induction machine

TABLE III. INDUCTION GENERATOR CHARACTERISTICS [11]

\begin{tabular}{|c|c|c|c|c|}
\hline $\mathrm{P}=660 \mathrm{~kW}$ & $\mathrm{Xs}=0.049 \mathrm{pu}$ & $\mathrm{Xr}=0.0589 \mathrm{pu}$ & $\mathrm{Xm}=2.88 \mathrm{pu}$ & $\mathrm{np}=2$ \\
\hline $\mathrm{V}=690 \mathrm{~V}$ & $\mathrm{Rs}=0.0064 \mathrm{pu}$ & $\mathrm{Rr}=0.006 \mathrm{pu}$ & $\mathrm{J}=29 \mathrm{~kg} / \mathrm{m} 2$ & $\mathrm{PF}=0.91$ \\
\hline
\end{tabular}

D. RCC System

Although there is no exact data about performance process of this system and its parameters, the control system illustrated in Figure 4 can be implemented with regard to the aim and role of RCC system in induction generators.

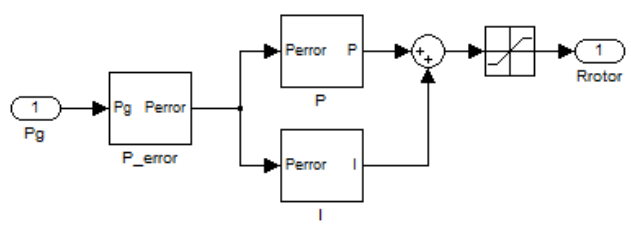

Fig. 4. Block diagram of RCC control system

In [12], rotor current signal is used to tune rotor path resistor. Here, the used control signal is the generator output power. This signal is compared with reference value $(660 \mathrm{~kW})$, i.e. generator rated power, and the error signal is obtained. The obtained error is employed on PI controller where the value of the resistor to be placed in rotor circuit is calculated. The value of external resistor of rotor in each phase is $1 \mathrm{ohm}$. Considering rotor/stator windings' turning ratio and p.u. impedance, its final boundary is 0.1 controlled by control limiting block.

\section{E. Pitch Angle Control System}

Here, speed quantity is used as a control signal. The role of this controller is to limit turbine rotation speed and, in turn, maintain output power at nominal value. Since the system is of mechanical type and blades' inertia is high, the performance of this system is lower than that of RCC method. When an abrupt wind over-speed occurs, RCC system starts operation. Then because of the thermal limit in resistors, the received power of wind is reduced by the increase in blades' angle. In Figure 5, the block diagram of the model can be seen [13]. The findings in [14] are used to calculate the parameters. The blocks of Servo part are used here in order to model the performance of blades' slow movement, resulting in changes of the angles of interest with a maximum rate of $5 \mathrm{deg} / \mathrm{s}$. The parameters are shown in Table IV. 


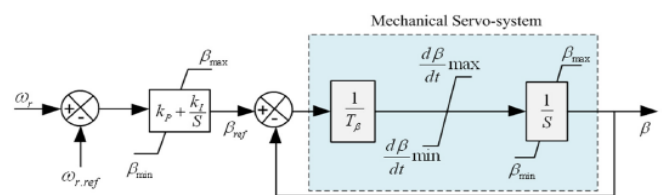

Fig. 5. Block diagram of blades angle control

TABLE IV. PARAMETERS OF BLADES ANGLE CONTROL

\begin{tabular}{|c|c|c|c|}
\hline $\mathrm{P}=100$ & Beta_min=0 & Rate_op $=5$ & Time Constant $=0.5$ \\
\hline $\mathrm{I}=20$ & Beta_max $=90$ & Rate_cl $=5$ & \\
\hline
\end{tabular}

\section{F. Capacitor Bank}

In Binalood wind farm, each unit is equipped with a capacitor bank of $250 \mathrm{kVAr}$ composed of two $50 \mathrm{kVAr}$ and two $75 \mathrm{kVAr}$ steps. Thus, two capacitors are used for each unit for modeling purpose as shown in Figure 1. The controller of each capacitor is regulated in a way that the minimum power factor in each unit is 0.95 . Delay time in operation of each step is 0.5 seconds.

\section{G. Electrical Grid}

The set of elements and devices in the grid are simulated by existing models in the software. Electrical characteristics of these elements are shown in Table V.

TABLE V. Parameters of Blades ANGLE Control

\begin{tabular}{|l|l|l|l|l|}
\hline $\begin{array}{l}\text { Transforme } \\
\text { r }\end{array}$ & 20 kV line & $\begin{array}{l}\text { Power } \\
\text { transformer }\end{array}$ & Load & $\begin{array}{l}\text { Power } \\
\text { Grid }\end{array}$ \\
\hline $\mathrm{S}=800 \mathrm{kva}$ & wiretype: $\mathrm{DOG}$ & $\mathrm{S}=230 \mathrm{Mva}$ & $\mathrm{P}=30$ & $\mathrm{Ssc}=1370$ \\
$\mathrm{Uk}=6 \%$ & $\mathrm{R}=0.273 \Omega / \mathrm{km}$ & $\mathrm{Uk}=12 \%$ & $\mathrm{MW}$ & $\mathrm{MVA}$ \\
$\mathrm{DYn5}$ & $\mathrm{X}=0.346 \Omega / \mathrm{km}$ & YnD11 & $\mathrm{Q}=10$ & $I_{k}^{\prime \prime}=6 K A$ \\
& & Tap numb: 19 & $\mathrm{Mvar}$ & $\mathrm{X} / \mathrm{R}=4.3$ \\
\hline
\end{tabular}

\section{POWER ANGLE IN INDUCTION MACHINE}

From the machine terminal, by the change of parameter $\mathrm{s}$, the generator will act as variable impedance that is dependent on s. Magnetizing current amplitude is approximately independent of the slip value and is negligible in comparison to the rotor current in normal operating condition. Thus, the stator is obtained in permanent mode by the following relationship:

$$
V_{S} \approx\left(R_{S}+j X_{S}+\frac{R_{r}}{s}+j X_{r}\right) I_{S}=(R+j X) I_{S}
$$

In order to calculate the power angle of the induction machine, the vector $V_{s}$ is taken as a reference vector. Thus, the power angle is defined by:

$$
\varphi=\tan ^{-1}\left(\frac{\operatorname{Im}\left(I_{S}\right)}{\operatorname{Re}\left(I_{S}\right)}\right)=\tan ^{-1}\left(-\frac{X}{R}\right)
$$

Since the slip is negative, the power angle will be positive. Induction machine active power is obtained by (7) in permanent operating condition:

$$
P=R I_{S}^{2}=\frac{V_{S}^{2}}{2 X} \operatorname{Sin} 2 \varphi
$$

The above equation states the relationship between the machine active power and the power angle. By the use of power angle, one can obtain the generator stability range. The higher this angle the higher the possibility for the generator to approach the non-stability region. The maximum power angle for which the generator remains stable depends on the generator characteristic and its operating point. A typical curve is illustrated in Figure 6. Here, the generator is stable when power angle during disturbance does not go beyond $\varphi_{2}$.

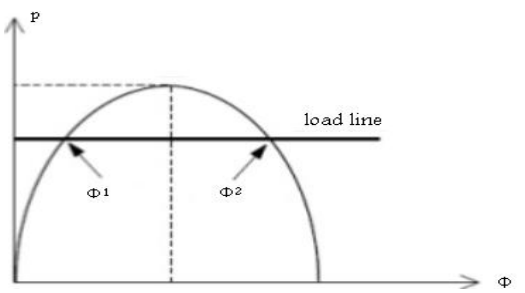

Fig. 6. Power-angle curve for induction generator

\section{DISTURBANCE AND WIND FARM BEHAVIOR}

The behavior of the wind farm is examined when a voltage drop appears on $20 \mathrm{kV}$ bus according to Figure 7. The trend of changing output active and reactive power of the wind farm is shown in Figure 8. By the reduction of voltage, the produced active power reduces and so does the consumed reactive power. For a moment, the wind farm acts as a reactive power producer due to capacitor banks. Reactive power production leads to a reduction in voltage drop due to fault occurrence in initial time. This helps us to improve stability. Nevertheless, the fault current also increases. Once the voltage recovers, the output reactive power increases instantly, approaching to its initial value. Meanwhile, the speed of the generator also decreases until it reaches its initial value. However, due to rotor inertia, the reduction amount will be negligible. Figure 9 shows the changes of speed and angles of blades during fault appearance.

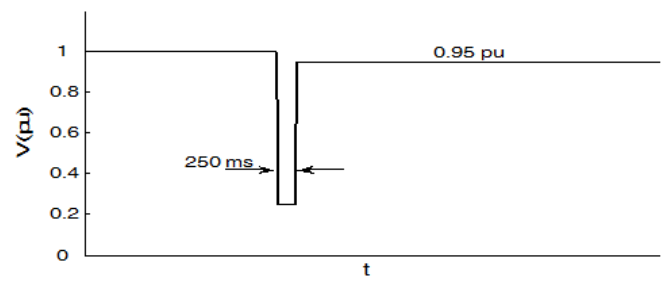

Fig. 7. The experienced voltage drop

\section{WIND FARM STABILITY ENHANCEMENT APPRACH}

\section{A. Rotor Resistance Increase}

According to (6), it can be found that if the rotor resistance is high, the power angle will be small. Small power angle requires more time in order to reach its critical speed. Thus, it can be asserted that the generator has higher stability. However, with RCC system, one can assert that until a fault 
remains, this system stops to operate because the output power is less than the nominal power. After voltage restoration, an external resistor is inserted into the circuit due to power oscillations when the output power is more than the nominal power. Although the insertion of external resistor intensifies the speed oscillations, it alleviates the power oscillations.

There is no necessity to have RCC system in order to increase rotor resistor; it is adequate to have the winding rotor type generator with available terminals. Consequently, a constant external resistor should be inserted into the rotor circuit. The resistor is normally short-circuited by a switch. It is brought to the circuit by opening that switch. In order to evaluate the behavior of such system, simulation results of a wind generating unit without/with switching resistor are illustrated in Figure 10 and 11.

The mentioned resistor with a value of 0.1 p.u. is connected to the grid immediately after fault occurrence. Here, faults with a long-time are ignored for the better comparisons to a system with an external resistor. Figure 10 depicts unit response to a $400 \mathrm{~ms}$-fault without the external resistor. It can be observed that the generator becomes unstable and its speed growth continues. Figure 11 shows the response with an external resistor without any reactive power compensation. This resistor should remain in the circuit at least $850 \mathrm{~ms}$ to help increase generator stability. That is, the resistor should stay in the rotor circuit after fault clearance. In fact, the main contribution of the resistor is after the fault which can be justified from another perspective. With voltage restoration and rotor current rise, power loss increases in the mentioned resistor such that the sum of generator output power will be less than the input mechanical power and its stability is confirmed by generator speed reduction. Based on the simulations, even if the resistor is inserted into the circuit after fault clearance, it will enhance the generator stability. Thus, there will be no problem even though a delay exists in fault detection and rotor resistor insertion into the circuit.

\section{B. Rotor Inertia Increasing}

According to the oscillation equation of electrical machines, speed changes due to the difference between mechanical and electrical torques depending on machine inertia. When a fault occurs, more time is required for heavier wind turbine to increase the rotor speed and for the generator to reach the non-stable region. Accordingly, by increasing rotor mass and inertia, the unit stability will be increased. Beside generator stability improvement, this will aid in decreasing sudden oscillations in turbine speed due to wind speed swings [16]. Additionally, the reduction of oscillations leads to reduced generator output power changes, improving the delivered power quality. Considering a fault time of $400 \mathrm{~ms}$, a $70 \%$ increase in inertia constant of generators leads to wind farm stability without reactive power compensation.

As shown, with the increase in inertia, the units' speed growth drops when a fault occurs and since reactive power of the induction generator is proportional to the speed, the absorbed reactive power from the grid reduces. However, inertia rise causes mechanical oscillations to be reduced. Mechanical oscillation frequency, therefore, comes closer to the grid natural frequency. This not only decreasing the output power quality, but also leads to Subsynchronous Resonance (SSR) and swing instability. The result in the long-term is extreme damages to the turbine shaft. Further, high inertia in mechanical parts of the system results in a difficulty of halting turbine operation in emergency conditions.
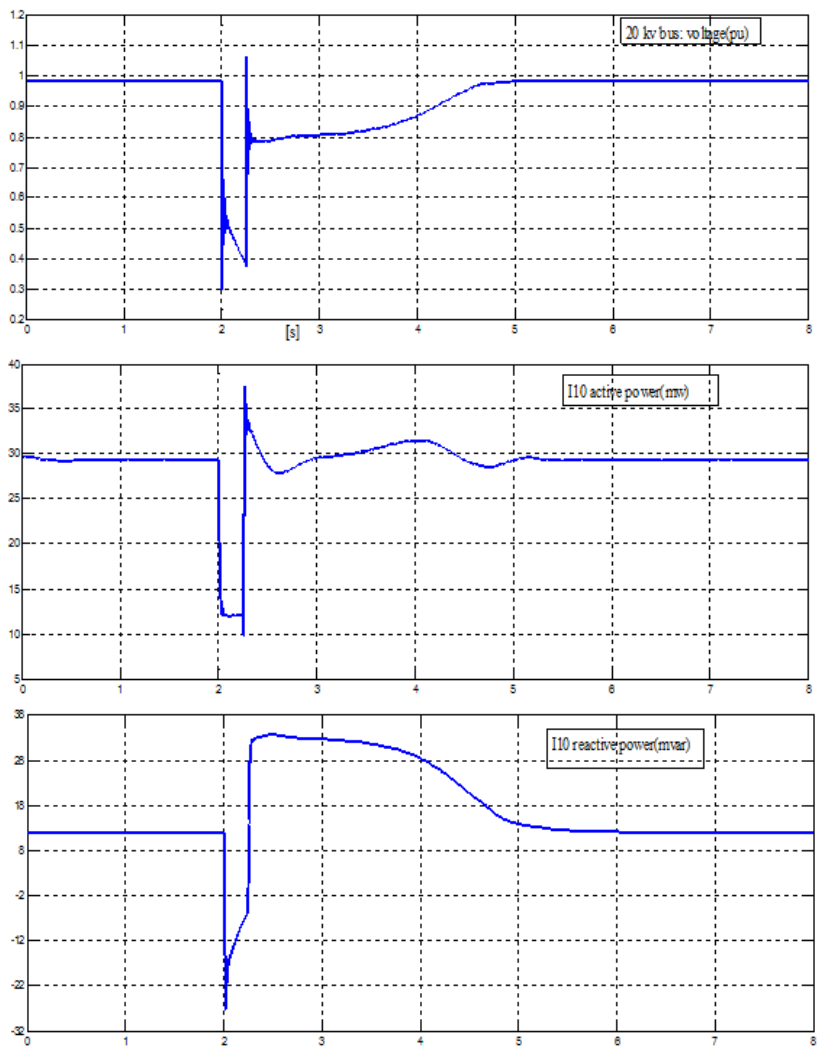

Fig. 8. The trend of changing output active and reactive power of the wind farm during a disturbance in $20 \mathrm{kV}$ bus
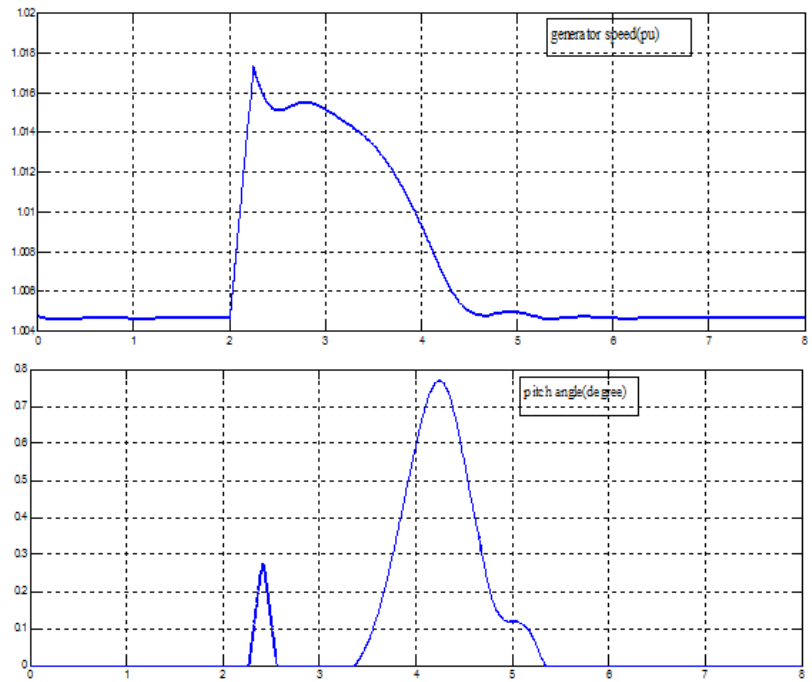

Fig. 9. Reaction of a unit during the fault in the main bus of the power plant 

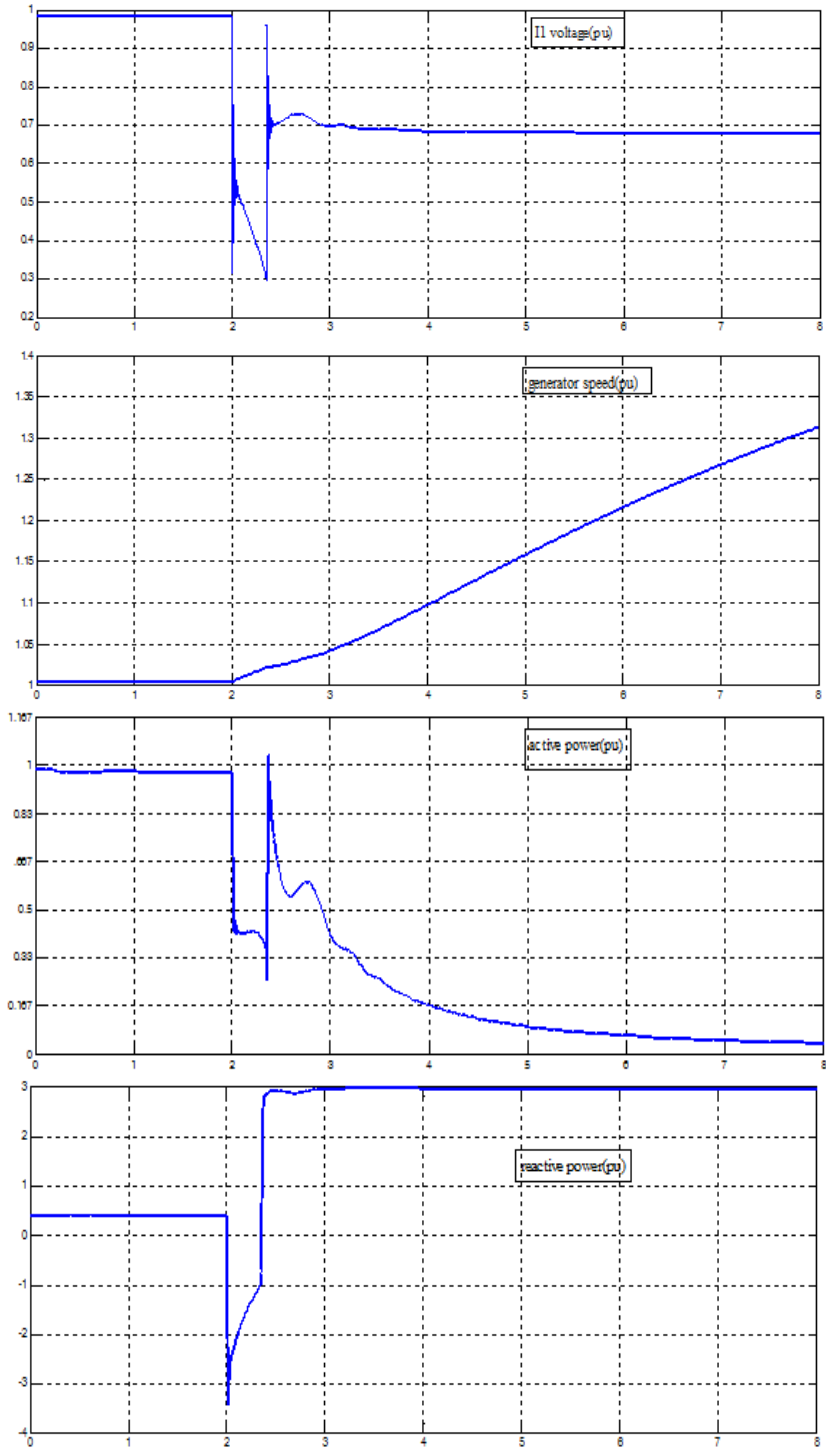

Fig. 10. Power plant instability during the fault without an external resistor

\section{Grid Reactance Decreasing}

Another approach to increase stability is to reduce the available reactance between the grid and wind farm. Based on (6), a reduction of reactance, (transformer, transmission line and generator reactance), will decrease the power angle and, thus, increase stability. It should also be noted that changing the reactance of transformers, transmission lines and generators is not always viable. By decreasing path reactance by $50 \%$, the system will become stable without the need of any reactive power compensation. The increase in total resistance of the path, based on (6), can improve stability. The increase in shortcircuit level and harmonics pollution are among the main disadvantage of the method.

\section{Reactive Power Injection}

During fault occurrence, capacitor banks are unable to produce adequate reactive power; specially, when the wind farm is connected to a weak grid. Thus, the flux of stator and rotor decrease, leading to reduced electric power. This, in turn, results in acceleration of turbine and generator. Reactive power injection at the instant of fault occurrence increases voltage level and, in turn, power transferred from generator to the power grid. So, generator acceleration and magnetic flux reduction are avoided. For exact and timely injection of reactive power, dynamic injector such as STATCOM and SVC should be used. The amount of reactive power injected depends on voltage drop and grid reactance. The lower the voltage drop and the higher the grid reactance, the less reactive power is required to maintain generator stability. Figure 14 shows simulation results for the least required capacity to keep generator stability. The capacity is $15 \mathrm{kVAr}$ which is huge compared to the wind farm generated power. If the generated reactive power is considered as a back-up for compensation of unit fault, the required capacity for this unit will again be high.
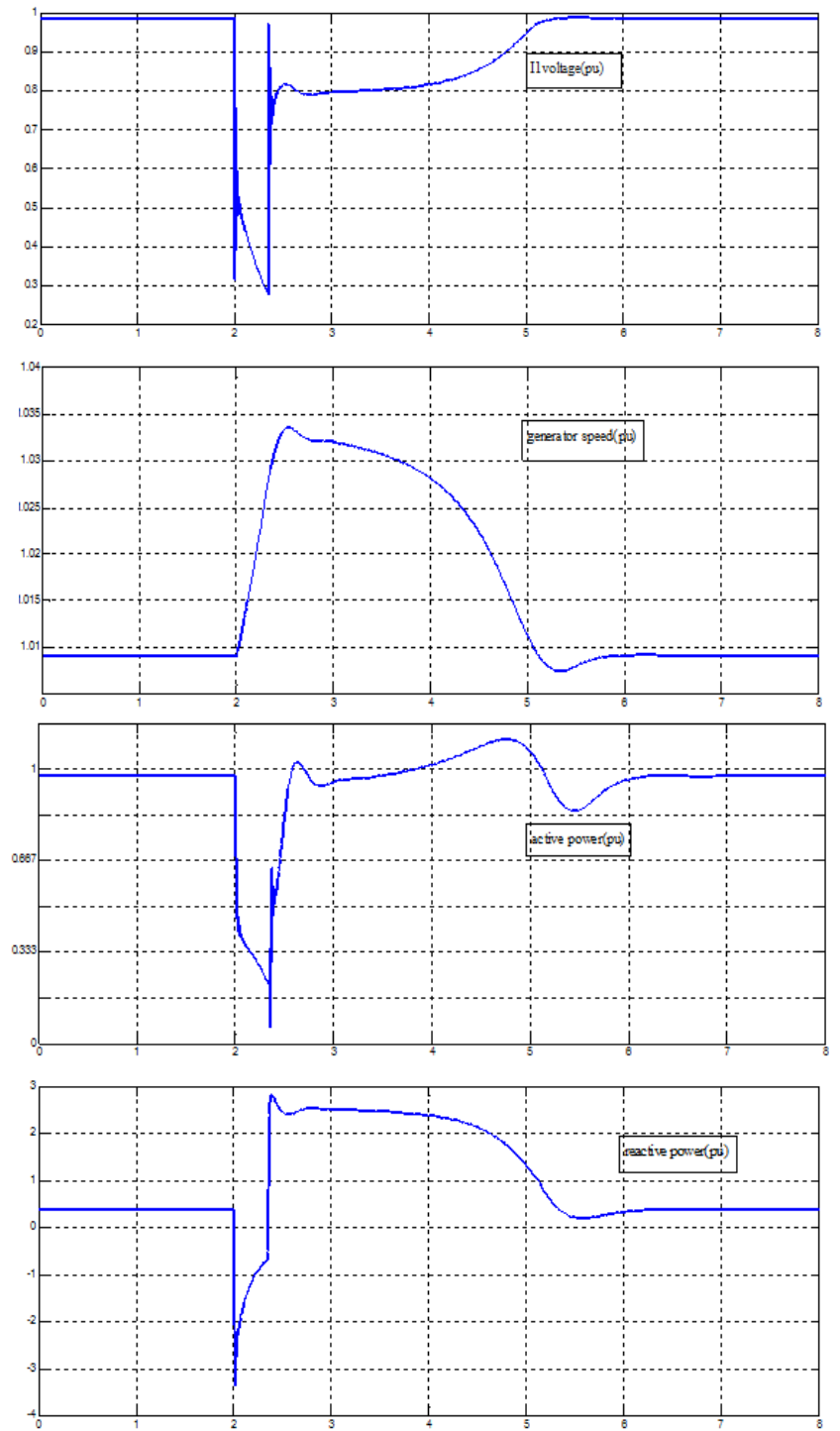

Fig. 11. The response of a unit of the wind farm during the fault (switching resistor in rotor) 

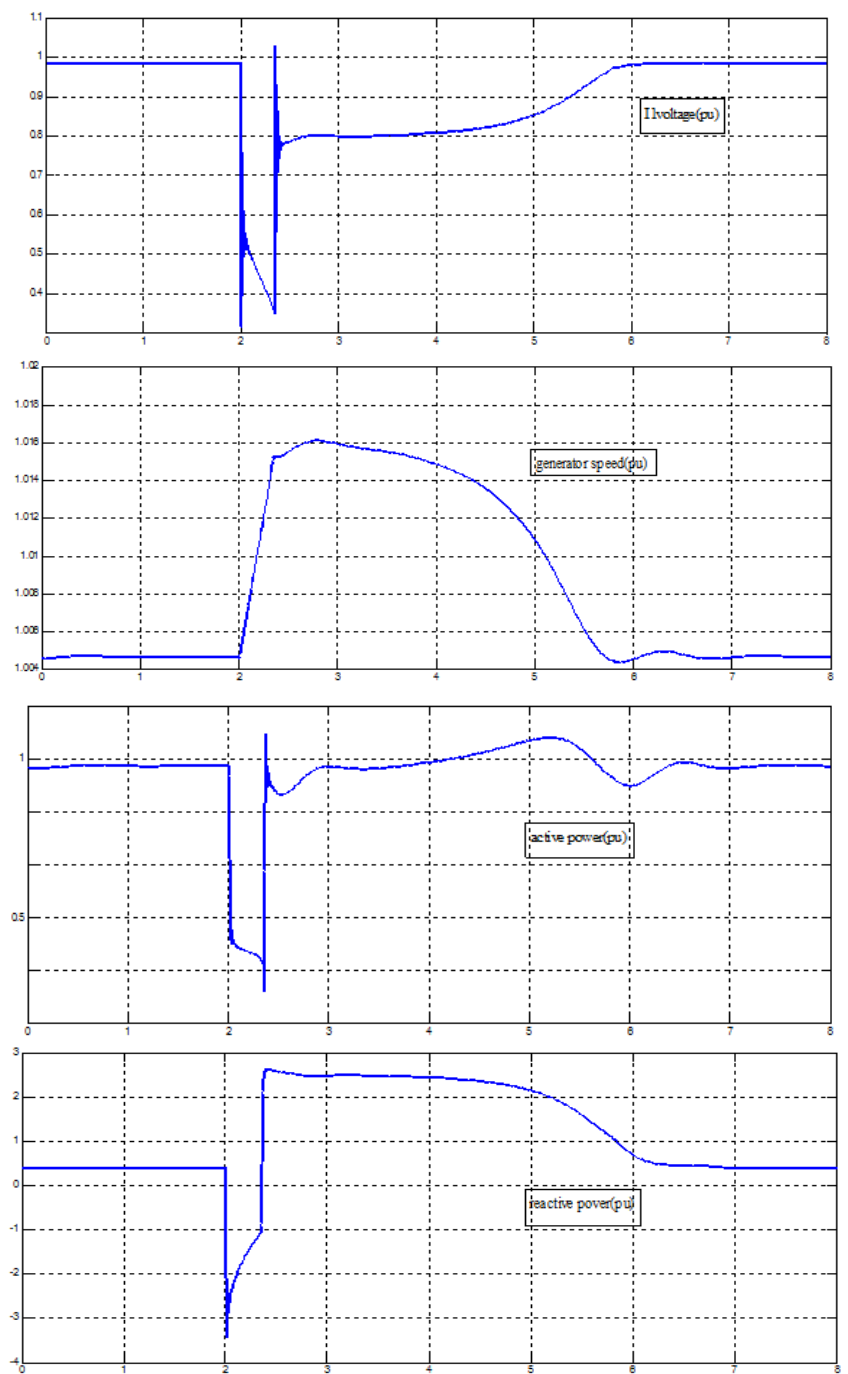

Fig. 12. The response of a unit of the wind farm during the fault $(70 \%$ increase in inertia constant).

\section{DISCUSSION}

For Binalood wind farm of V47 Model and Optislip design from Danish company, VESTAS, and close-to-real world external grid, there is a need to use at least $15 \mathrm{MVAr}$ reactive power compensation using FACTS devices. However, reactive power compensation unit capacity can be reduced by two ways:

1. Optimization of electrical and mechanical characteristics of wind farm

1. Operational improvement of wind farm controllers such as blades' angle control system and generator's electrical characteristics during a fault

By improving wind farm characteristics, one can reduce the compensation unit capacity by a half. In addition, it was found that by taking some operational improvements in generators and grid, there may be no need to inject reactive power to provide wind farm stability. The use of FACTS devices not only maintain generator stability, but also compensate reactive power, eliminate flickers produced by generator, and enhance delivered power quality to the grid. However, there is a need for a high capacity of 15 MVAr, imposing high cost to the system.
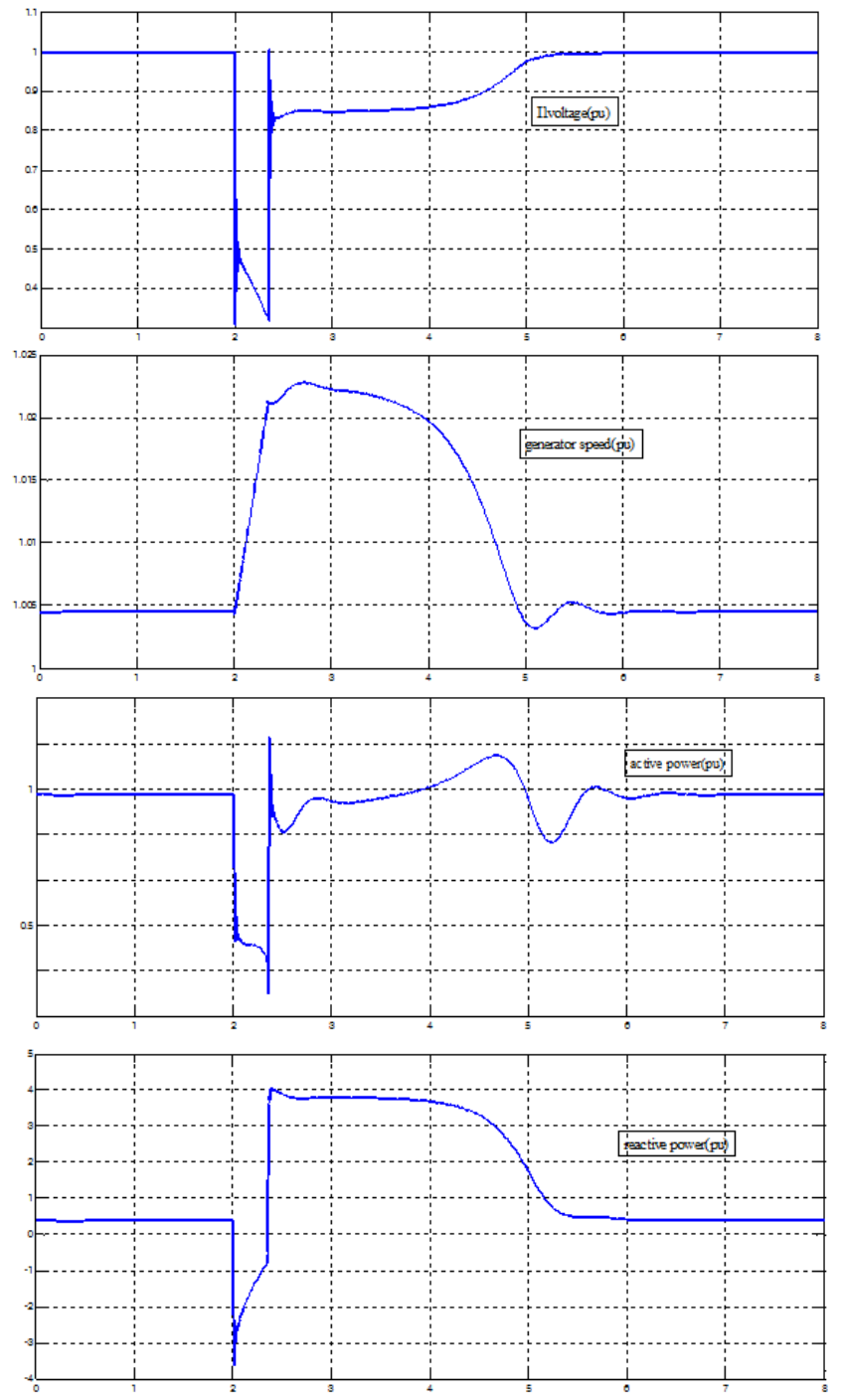

Fig. 13. The response of a unit of the wind farm during the fault $(50 \%$ decreas in path reactance)

In Binalood wind farm, since the generating units have winding type rotors, the addition of a rotor resistor during fault occurrence is a viable option. In this paper, simulations have been completed based on the least required resistor. Of course, simply by selecting a larger resistor not only stability margin is increased, stator and rotor currents are also reduced. Moreover, the presence of a resistor leads to increased damping and, compared to the other methods, oscillations are damped fast. It was shown that grid reactance reduction is also an appropriate method. But, a reduction of grid reactance results to an increased short-circuit level. Inertia growth method and change of generator's other parameters are not always possible or at least is a burdensome task that can be done only by the manufacturer. In designing a generator and its parameters, all involving factors should be considered aiming at the type of 
usage. Improving the operation of wind farm controllers can be very effective in maintaining stability. For example, power angle control systems in wind farms equipped with these systems, such as Binalood wind farm, is merely used for optimization of wind farm output power versus input wind amount and they have no response when a fault occurs until the speed of wind generator reaches critical region. Correction of this operation is very influencing on system stability.
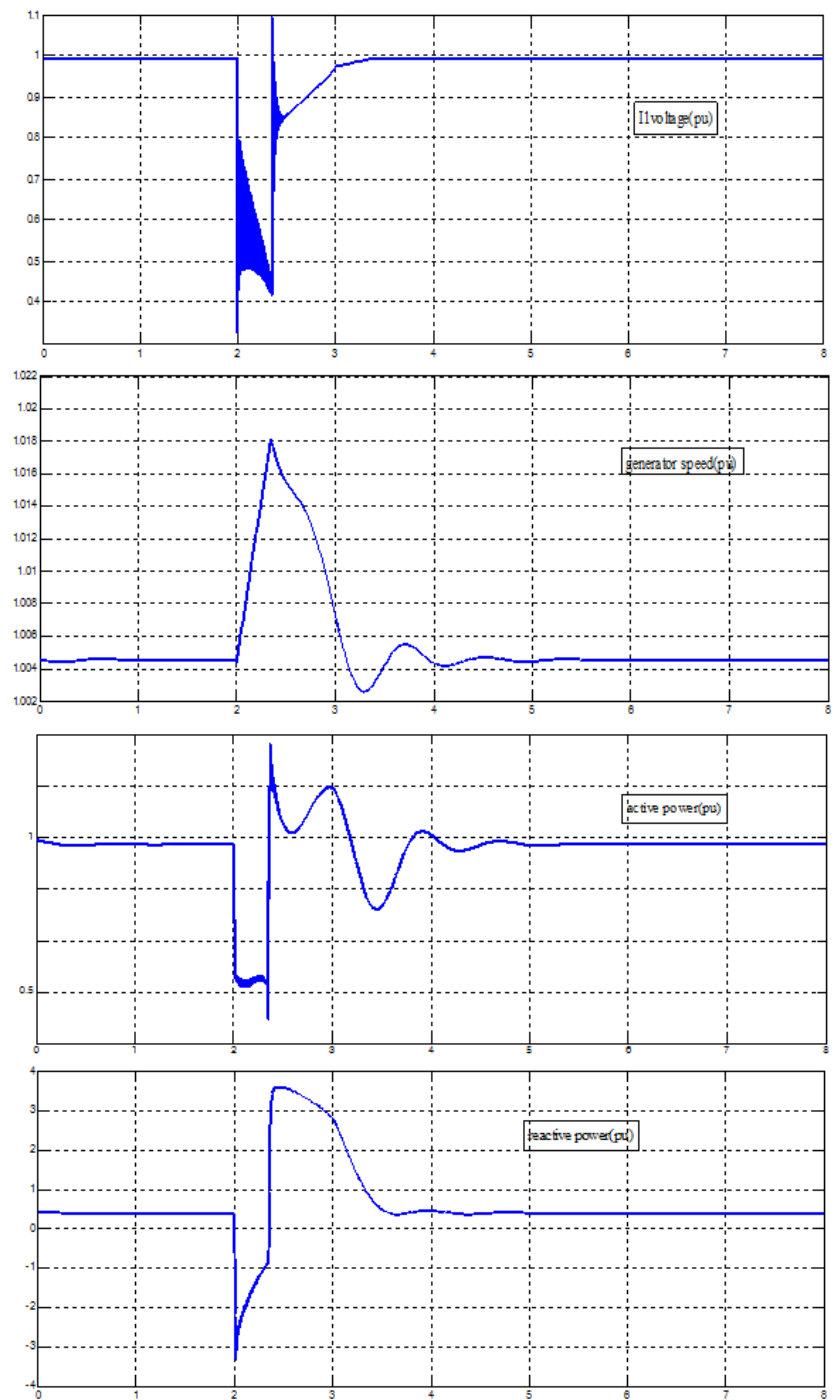

Fig. 14. The response of a unit of the wind farm during the fault with reactive power injection via STATCOM

\section{CONCLUSION}

Considering the increase in wind farms' penetration to power systems, stability of a wind farm and its connectivity to the grid during fault occurrence and grid disturbances are vital issues. In this paper, several methods have been examined for the improvement of a wind farm's stability. Different methods are employed to enhance stability when a near-by disturbance occurs. Simulations are carried out using Matlab and Simulink.
Results are investigated and discussed and the different approaches are compared.

\section{ACKNOWLEDGMENT}

Funding support of this research was provided by the Ramhormoz branch, Islamic Azad University, Ramhormoz, iran. Moreover this paper was derived from a report named "Specify the best transient stability support method in Binalood wind farm with Optislip wind turbine During Disturbance".

\section{REFERENCES}

[1] V. Akhmatov, H. Knudsen, A. H. Nielsen, J. K. Pedesen, "Modeling and Transient Stability of Large Wind Farms", Electrical Power Energy System, Vol. 25, pp. 123-144, 2003

[2] T. Sun, Z. Chen, "Voltage Recovery of Grid-Connected Wind Turbine after a Short-Circuit Fault", IEEE 35th Annual Power Electronics Specialists Conference, Vol. 3, pp. 1991-1997, 2004

[3] K. Rajambal, B. Umamaheswari, C. Chellamuthu, "Electrical Braking of Large Wind Turbines", Renewable Energy, Vol. 30, pp. 2235-2245, 2005

[4] M. G.Kanabar, S. A. Khaparde, "Rotor Speed Stability Analysis of Constant Speed Wind Turbine Generators", 2006 International Conference on Power Electronic, Drives and Energy Systems, pp. 1-5, 2006

[5] V. Agarwal, R. K. Aggarwal, P. Patidar, C. Patki, "A novel scheme for rapid tracking of maximum power point in wind energy generation systems", IEEE Trans. Energy Convers., Vol. 25, No. 1, pp. 228-236, 2010

[6] H. Famesh, Guidelines for Design of Wind Turbines, Wind Energy Department, Risø National Laboratory, 2002

[7] F. Iov, A. D. Hansen, P. Sorensen, F. Blaabjerg, Wind Turbine Blockset in Matlab/Simulink, Aalborg University, 2014

[8] I. Boldea, Electrical Machines and Transformers, Ed. Didactica si Pedagogica, 1994

[9] P. C. Krause, O. Wasynczuk, S. D. Sudhoff, Analysis of Electric Machinery, IEEE Press, 1995

[10] P. Pillay, V. Levin, "Mathematical models for induction machines", IEEE Industry Applications Conference, Thirtieth IAS Annual Meeting, Vol. 1, pp. 606-616, 1995

[11] M. Barakat, S. Elmasry, M. E. Bahgat, A. A. Sayed, "Effect of Rotor Current Control for Wound Rotor Induction Generator on the Wind Turbine Performance", International Journal of Power Electronics and Drive Systems, Vol.2, No. 2, pp. 117-126, 2012

[12] D. J. Burnham, S. Santoso, "Variable rotor resistance control of wind turbine generators", IEEE power and energy society general meeting, pp. 1-6, 2009.

[13] V. Le , X. Li, Y. Li, T. L. T. Dong, C. Le, "An Innovative Control Strategy to Improve the Fault Ride-Through Capability of DFIGs Based on Wind Energy Conversion Systems", Energies, Vol. 9, No. 2, Art. No. 69, pp. 1-23, 2016

[14] G. Ofualagba, E. Ubeku, "Wind Energy Conversion system: Wind Turbine Modeling", IEEE Proceeding On Power And Energy Society General Meeting - Conversion And Delivery Of Electrical Energy In The 21st Century, pp. 1-8, 2008

[15] A. Petersson, Analysis, Modeling and Control of Doubly-Fed Induction Generators for Wind Turbines, Chalmers University of Technology, Goteborg, Sweden, 2005

[16] A. G. G Rodriguez, M. B. Payan, C. I. Mitchell, "PSCAD based simulation of the connection of a wind generator to the network", IEEE Power Tech Proceedings, Porto, 10-13 Sept. 2001 